\title{
HYPER-RESPONSIVENESS OF ALDOSTERONE TO METOCLOPRAMIDE IN ALDOSTERONISM
}

\author{
T. C. GNIADEK, R. J. GREKIN, M. D. GROSS AND J. Z. VILLAREAL \\ Division of Endocrinology, The University of Michigan and the Veterans Administration \\ Medical Center, Ann Arbor, Michigan 48109, USA
}

(Received 16 June 1981, revised 6 October 1981, accepted 19 November 1981)

\section{SUMMARY}

Metoclopramide, a dopamine antagonist, stimulates aldosterone secretion in normal man. We studied the response of plasma aldosterone, plasma renin activity, cortisol, sodium, potassium and serum prolactin to a 10 -mg intravenous dose of metoclopramide in six dexamethasone suppressed patients with aldosteronism (four with adrenal adenoma, two with bilateral adrenal hyperplasia) and in six dexamethasone suppressed normal male volunteers. All subjects were studied on an ad libitum sodium diet. Patients were supplemented with oral potassium prior to study.

Sodium and potassium were not different between groups and did not change following metoclopramide. Cortisol was suppressed to less than $3 \mu \mathrm{g} / \mathrm{dl}$ throughout the study in all subjects. Basal plasma renin activity was significantly lower in the patients as compared with controls $(P<0.05)$, and did not change in either group following metoclopramide.

Basal aldosterone levels were not significantly different in patients as compared with controls, although patients did tend to have higher levels. The incremental and integrated response of aldosterone to metoclopramide in patients was significantly greater than controls $(P<0.01)$. The percentage increase in aldosterone was greater than controls in five of the six patients.

Basal prolactin was higher in the patients than in the controls. All subjects had a significant rise in prolactin to metoclopramide $(P<0.05)$. Five of six patients had an increased response of prolactin when compared to the controls and the four female patients had a significantly greater rise in prolactin as compared to the normals $(P<0.01)$.

These data suggest that increased dopaminergic activity plays a compensatory role in inhibiting aldosterone secretion in patients with aldosteronism. It appears unlikely that a decrease of dopaminergic inhibition is involved in the pathogenesis of aldosteronism due to either adenoma or bilateral hyperplasia.

Metoclopramide, a dopamine antagonist, acutely stimulates aldosterone secretion in Correspondence: Dr R. J. Grekin, 2215 Fuller Road, Ann Arbor, Michigan 48105, USA 0300-0664/82/0500-0475\$02.00 (C) 1982 Blackwell Scientific Publications 
normal man (Norbiato et al., 1977). This action of metoclopramide can be blunted in a competitive dose-dependent fashion by preinfusion of dopamine (Noth et al., 1980; Carey et al., 1980). Moreover, metoclopramide stimulates aldosterone secretion in hypopituitary and bilaterally nephrectomized man (Pratt et al., 1979). Metoclopramide has no effect on the metabolic clearance rate of aldosterone stimulating peptide (Brown et al., 1979b). Metoclopramide also enhances the aldosterone output of zona glomerulosa cells from hyperplastic and adenomatous adrenal tissue in vitro (Brown et al., 1979a). This evidence supports a direct stimulatory action of metoclopramide on aldosterone output of the adrenal zona glomerulosa.

Both the presence and the absence of a response of plasma aldosterone to metoclopramide have been reported in patients with aldosteronism (Brown et al., 1979a; Bevilacqua et al., 1980). To investigate whether metoclopramide indeed has an effect upon plasma aldosterone in hyperaldosteronism and whether dopamine is involved in the pathogenesis of hyperaldosteronism, we studied the aldosterone response to intravenous metoclopramide in six patients with hyperaldosteronism and in six normal subjects.

\section{METHODS}

After informed consent, all subjects were studied in the Clinical Research Center of the University of Michigan. Six patients with hyperaldosteronism were studied. This diagnosis was confirmed in each patient by measurement of 24-h urinary aldosterone, recumbent and upright plasma renin activity and plasma aldosterone under conditions of $150 \mathrm{mEq}$ and $10 \mathrm{mEq}$ sodium diet.

The six patients consisted of four women and two men. Three patients (two women and one man) had adrenal adenomata confirmed by bilateral adrenal venous aldosterone determination. Of these, one woman had an adenoma confirmed histologically. One man was presumed to have adenoma due to the high level of his aldosterone secretion and lateralization of uptake to the left on adrenal scintigraphy, but attempts to obtain right adrenal vein blood at adrenal vein catheterization were unsuccessful. Two female patients had bilateral adrenal hyperplasia. One woman had bilateral hypersecretion of aldosterone confirmed by adrenal vein catheterization and bilateral uptake on adrenal scintigraphy. The other patient's diagnosis of hyperplasia was based upon the mildness of her abnormality in aldosterone secretion and early bilateral uptake on adrenal scintigraphy. The control group consisted of six normotensive normal male volunteers taking no medication.

All subjects were studied on an ad libitum sodium diet. Prior to study, patients were withdrawn from all medications for at least 3 weeks, except for two patients who required $\alpha$-methyldopa for severe hypertension. All patients were supplemented with oral potassium prior to the study. All patients and volunteers received dexamethasone $(0.5$ $\mathrm{mg}$ ) every $6 \mathrm{~h}$ for $72 \mathrm{~h}$ prior to study. The patients were supine and fasting from $2200 \mathrm{~h}$ the night prior to study. The normal controls were fasting from $2200 \mathrm{~h}$ and were supine for at least $1 \mathrm{~h}$ prior to the beginning of basal sampling.

Blood samples were obtained through an indwelling catheter kept patent with a dilute heparinized saline solution. Blood for plasma aldosterone was obtained at $-60,-40$, $-20,0,15,30,60,90$, and $120 \mathrm{~min}$. Plasma renin activity was obtained at 0,30 , and 120 min. Plasma cortisol, serum sodium, and serum potassium were measured at 0,60 , and $120 \mathrm{~min}$. Serum prolactin levels were measured at 0 and $30 \mathrm{~min}$. A single $10 \mathrm{mg}$ dose of 
metoclopramide was given intravenously at time zero. There were no side effects from the injection.

Plasma aldosterone, plasma renin activity, and plasma cortisol were measured by radioimmunoassay (Antunes et al., 1976; Cohen et al., 1971; Dash et al., 1975). Serum prolactin was measured by radioimmunoassay by the University of Michigan Ligand Assay Laboratory. Prolactin antiserum was obtained from Radioassay Systems Laboratory, Inc., Carson, California, and prolactin substrate from Calbiochem-Behring Corp., La Jolla, California. Serum was incubated for $24 \mathrm{~h}$ with antiserum and then ${ }^{125} \mathrm{I}$ labelled prolactin was added followed by another $24 \mathrm{~h}$ of incubation. Following this, separation was performed with sheep anti-rabbit globulin. Serum sodium and serum potassium were measured by Autoanalyzer.

Statistical analysis was accomplished by use of the signed rank test within groups and two sample rank test between groups (Neter \& Wasserman, 1974). Results are expressed as means $\pm \mathrm{SEM}$.

\section{RESULTS}

There were no significant differences in basal sodium and potassium levels between patients and normals, although patients tended to have lower potassium levels. Serum sodium and potassium levels were unaltered after metoclopramide administration. Cortisol was less than $3 \mu \mathrm{g} / \mathrm{dl}$ throughout the study in all subjects, and was usually below the lower limits of detection of the assay $(0.78 \mu \mathrm{g} / \mathrm{dl})$.

Basal plasma renin activity was significantly lower in the patients with hyperaldosteronism as compared with normals $(P<0.05)$. There was no significant change in plasma renin activity following metoclopramide in either group (Table 1).

Basal aldosterone did not differ significantly between the two groups, although patients had a higher mean basal level than normals $(21 \cdot 6 \pm 4 \cdot 8$ v. $6 \cdot 2 \pm 0 \cdot 81 \mathrm{NS})$. Fig. 1 shows the aldosterone response to metoclopramide in the normals and patients with hyperaldosteronism. Peak aldosterone levels occurred at 15 or $30 \mathrm{~min}$ following metoclopramide in all normals and all but one of the patients. The incremental response between basal and peak levels was significantly greater in the patients than in the normal controls $(112 \cdot 1 \pm 35 \cdot 7$ $\mathrm{ng} / \mathrm{dl}$ v. $11 \cdot 2 \pm 2 \cdot 6 \mathrm{ng} / \mathrm{dl} P<0 \cdot 01)$. The percentage change in aldosterone was greater in

\begin{tabular}{|c|c|c|}
\hline \multirow[b]{2}{*}{ Time } & \multicolumn{2}{|c|}{$\begin{array}{l}\text { Plasma renin activity } \\
\qquad(\mathrm{ng} / \mathrm{ml} / \mathrm{h})\end{array}$} \\
\hline & Patients & Normals \\
\hline 0 & $0.45 \pm 0.23 *$ & $1.85 \pm 0.4$ * \\
\hline 30 & $0.47 \pm 0.23$ & $1 \cdot 72 \pm 0 \cdot 24$ \\
\hline 120 & $0.44 \pm 0.25$ & $1.69 \pm 0.41$ \\
\hline
\end{tabular}

$* P<0.05$. 
five of six patients than in any of the controls. One patient had a percentage change equal to the smallest percentage change in the normals. The mean percentage change for the patient group, therefore, approached but did not attain significance at the $P<0.05$ level when compared with the normals. Average values were $1116 \pm 442 \%$ for patients v. $280 \pm 24 \%$ for normals. The integrated aldosterone response was significantly greater in the patients than in the normal controls $(624 \cdot 4 \pm 222 \cdot 8$ v. $40 \cdot 9 \pm 8 \cdot 4 ; P<0 \cdot 01)$.

The basal prolactin was higher in patients than in controls; $59 \cdot 6 \pm 44 \cdot 3 \mathrm{ng} / \mathrm{ml} \mathrm{v}$. $4.5 \pm 0.66 \mathrm{ng} / \mathrm{ml}(P<0.01$ two sample rank test, NS by $t$ testing). Two patients had abnormally elevated basal levels. One male patient with presumed adrenal adenoma had a slightly elevated level of $30.7 \mathrm{ng} / \mathrm{ml}$ and one female patient with surgically documented adrenal adenoma had a level of $277.5 \mathrm{ng} / \mathrm{ml}$. This patient is currently being investigated for the presence of a prolactinoma. Both of these patients were taking $\alpha$-methyldopa at the time of the study.

Fig. 2 illustrates the basal to peak $(30 \mathrm{~min})$ prolactin response to metoclopramide in both normals and patients with primary hyperaldosteronism. All subjects had a significant $(P<0.05)$ rise in serum prolactin following metoclopramide. All but one male patient had a greater rise in serum prolactin than the normals. The incremental response in all patients, however, approached but did not achieve significance at $P<0 \cdot 05$. The incremental response was markedly greater in the four female patients $v$. the normal controls $(P<0 \cdot 01)$.

\section{DISCUSSION}

Evidence has recently accumulated that dopamine is involved in the control of

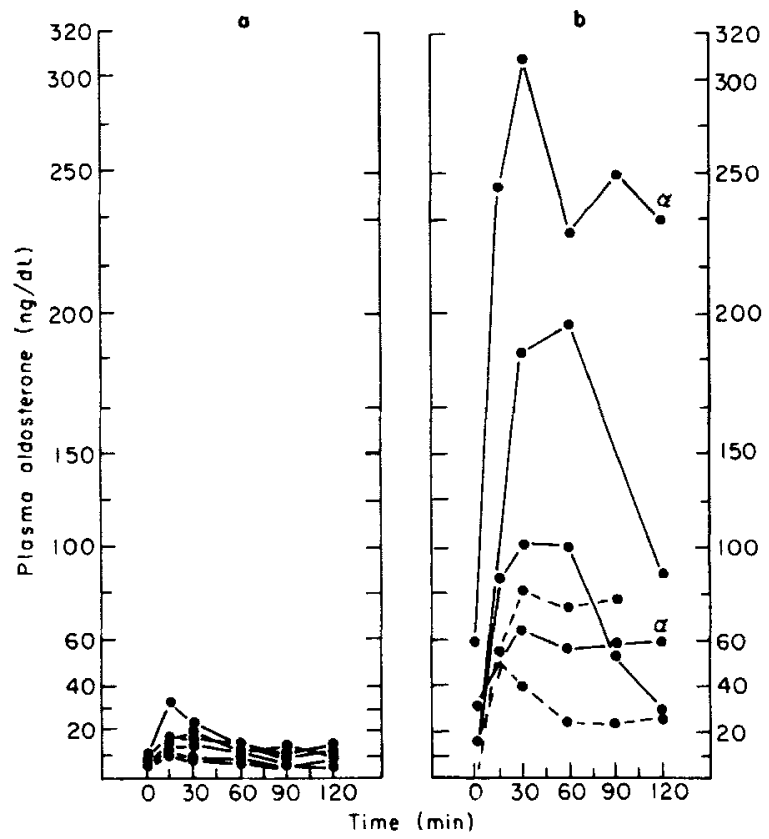

Fig. 1. Plasma aldosterone (ng/dl) in (a) normals and (b) patients with hyperaldosteronism (-adenoma; - - hyperplasia) before and after $10 \mathrm{mg}$ metoclopramide given intravenously during dexamethasone suppression. Patients taking $\alpha$-methyldopa are designated with $\alpha$. 


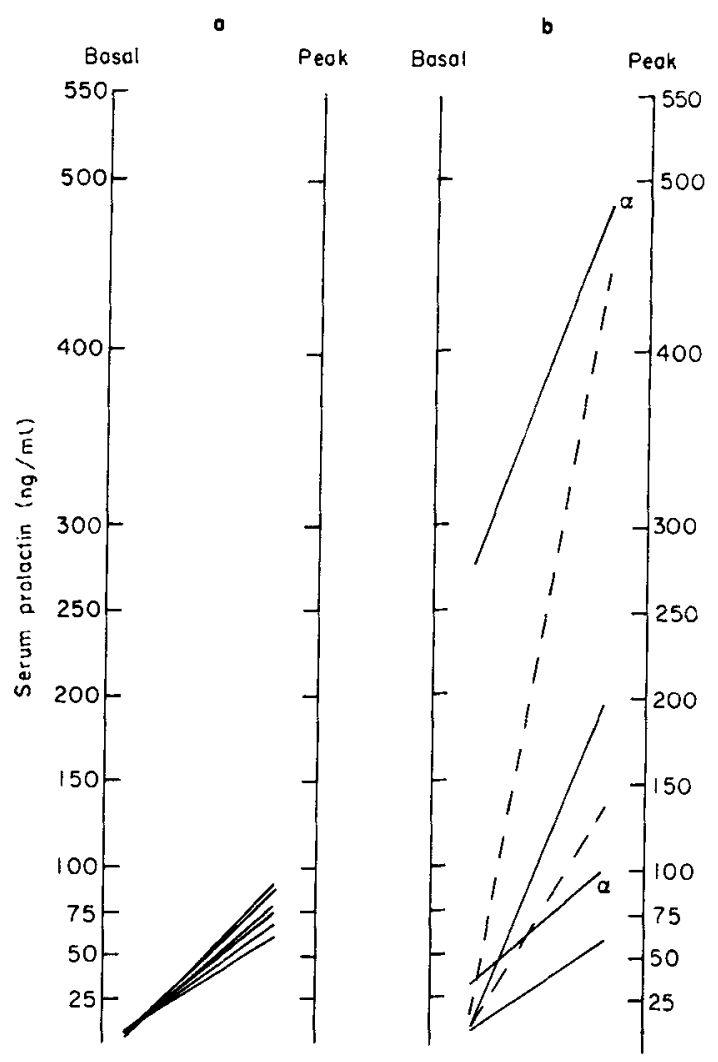

Fig. 2. Basal to peak serum prolactin (ng/ml) in (a) normals and (b) patients with hyperaldosteronism (- adenoma; - - - hyperplasia) after $10 \mathrm{mg}$ metoclopramide (i.v.). Patients taking $\alpha$-methyldopa are designated with $\alpha$.

aldosterone secretion in addition to angiotensin II, potassium, and ACTH. Whitfield et al. (1980) have shown that in normals on a 50-mEq sodium diet the aldosterone response to upright posture was blunted by bromocriptine, a dopamine agonist, without concomitant change in plasma renin activity. The authors also reported that the angiotensin II stimulated aldosterone response in these normals was suppressed by bromocriptine. Studies in vitro have shown that dopamine blunts the angiotensin II stimulated aldosterone response in isolated bovine adrenal glomerulosa cells. This effect was limited to the action of angiotensin II on the late phase of aldosterone secretion (McKenna et al., 1979). Bromocriptine does not affect basal levels of aldosterone stimulated by chronic low sodium diet (Semple \& Mason, 1978). This evidence supports a suppressive effect of dopamine on acute stimulatory responses of the adrenal zona giomerulosa in normals.

Some evidence exists that secretion of dopamine is directly proportional to sodium intake, as urinary dopamine rises with intravenous saline loading in sodium deprived normals (Alexander $e t$ al., 1974). If there is an associated increase in dopamine levels in the adrenal, this may mediate a compensatory fall in aldosterone in response to saline loading.

Investigations in patients with hyperaldosteronism have demonstrated that a dopaminergic mechanism may also be active. Kuchel et al. (1980) reported that patients with 
primary hyperaldosteronism have increased urinary and plasma dopamine levels. The rise in aldosterone produced by upright posture in two of these patients was accompanied by a decline in plasma dopamine levels; while one patient who failed to respond with a rise in aldosterone to upright posture had no change in plasma dopamine levels. These data suggest that dopamine also has an inhibitory role in the control of plasma aldosterone in patients with aldosteronism.

In the present study, serum prolactin responses were used as a marker of the antidopaminergic action of metoclopramide. The higher basal prolactin levels observed in the patients could be due to the fact that four of the patients with higher basal prolactins than the normals were female (Molitch \& Reichlin, 1980), and one male patient with a high basal prolactin level was taking $\alpha$-methyldopa (Pettinger et al., 1963). Both of these factors could then cause the basal prolactin to be higher in the patients when compared with the normal male controls. In this study, the four female patients had a marked rise in prolactin as compared with the male controls $(P<0.01)$. Females have previously been reported to have a somewhat greater response to metoclopramide than males, but this response did not achieve significance until $90 \mathrm{~min}$ after metoclopramide injection (Delitala et al., 1976). Also the reported levels achieved by normal females in that study were markedly lower than those seen in our female patients with aldosteronism (Delitala et al., 1976). Therefore, it seems unlikely that the observed difference in prolactin response can be explained by a difference in sex alone. This tendency to increased response of prolactin in the patients suggests increased pituitary dopaminergic inhibition.

The basal levels of aldosterone were not significantly different between the patients and the normals. This is probably due to the suppressive effect of dexamethasone on basal plasma aldosterone. The dexamethasone treatment also may have contributed to the response to metoclopramide since dexamethasone has been shown to increase plasma dopamine levels in patients with primary hyperaldosteronism (Kuchel et al., 1980).

From this study, it is clear that metoclopramide induced a marked rise in aldosterone levels in patients with hyperaldosteronism. The mechanism of this effect may be that in these patients the autonomous overproduction of aldosterone leads to sodium retention which then increases dopamine release. Further studies on urinary and plasma dopamine levels in patients with aldosteronism will be required to clarify this assumption. As in the normal state, sodium retention also suppresses the renin-angiotensin axis, but this suppression has little effect upon the overproduction of aldosterone by the adrenal glands of these patients. Therefore the inhibition of aldosterone secretion by dopamine may remain as a major modulator of plasma aldosterone levels. Blocking this inhibition with metoclopramide then markedly raises plasma aldosterone levels. A corollary to this effect is that it seems unlikely that a lack of dopaminergic inhibition is involved in the pathogenesis of hyperaldosteronism due to either adrenal adenoma or bilateral adrenal hyperplasia.

\section{ACKNOWLEDGEMENTS}

The authors acknowledge the technical assistance of Alan Vollmer, Yeh Chen and Elizabeth Struble, the help of the nurses of the clinical research center and the secretarial support of Constance Bachor.

This work was supported by grant HL18575 of the National Heart Lung and Blood Institute grant 5 MO1 RR42 from the division of research resources, and USPHS grant T32 AM 07245. 


\section{REFERENCES}

Alexander, R.W., Gill, J.R., Yamabe, H., LovenberG, W. \& Keiser, H.R. (1974) Effects of dietary sodium and of acute saline infusion on the interrelationship between dopamine excretion and adrenergic activity in man. Journal of Clinical Investigation, 54, 194-200.

ANTUNES, J.R., DALE, S.L. \& MELBY, J.C. (1976) Simplified radioimmunoassay for aldosterone using antisera to aldosterone- $\gamma$-lactone. Steroids, 28, 621-630.

Bevilacqua, M., Norbiato, G., Raggi, U., Micossi, P., Baggio, E. \& Prandelli, M. (1980) Dopaminergic control of serum potassium. Metabolism, 29, 306-310.

Brown, R.D., Hegstad, R. \& Hogan, M.J. (1979) Effect of metoclopramide, a dopamine antagonist, on aldosterone in primary aldosteronism. Clinical Research (Abstract), 27, 678A.

BROWN, R.D., KAO, P. \& JiANG, N.S. (1979) Metoclopramide acts directly on the adrenal cortex to stimulate the secretion of aldosterone. Clinical Research (Abstract), 27, 248A.

CAREY, R.M., THORNER, M.O. \& ORTT, E.M. (1980) Dopaminergic inhibition of metoclopramide-induced aldosterone secretion in man. Journal of Clinical Investigation, 66, $10-18$.

Cohen, E.L., Grim, C.E., Conn, J.W., Blough, Jr. W.M., GuYer, R.B., Kem, D.C. \& LuCas, C.P. (1971) Accurate and rapid measurement of plasma renin activity by radioimmunoassay. Results in normal and hypertensive people. Journal of Laboratory and Clinical Medicine, 77, 1025-1038.

Dash, A.J., ENGland, B.G. \& Midgley, A.R. (1975) Specific nonchromatographic radio-immunoassay for human plasma cortisol. Steroids, 26, 647-661.

Delitala, G., Masala, A., Alagna, S. \& Devilla, L. (1976) Effect of metoclopramide on serum prolactin levels in humans. Clinical Endocrinology, 5, 731-734.

Kuchel, O., Buu, N.T., Vecsei, P., Bourque, M., Hamet, P. \& Genest, J. (1980) Are plasma aldosterone surges in primary aldosteronism due to a loss of an inhibitory dopaminergic control? Journal of Clinical Endocrinology and Metabolism, 51, 337-344.

MCKenNa, T.J., IsLand, D.P., Nicholson, W.E. \& Liddele, G.W. (1979) Dopamine inhibits angiotensin-stimulated aldosterone biosynthesis in bovine adrenal cells. Journal of Clinical Investigation, 64, 287-291.

MoLITCH, M.E. \& REICHLIN, S. (1980) The amenorrhea, galactorrhea and hyperprolactinemia syndromes. Advances in Internal Medicine, 26, 37-66.

Neter, J. \& Wasserman, W. (1974) Applied Linear Statistical Models, R. D. Irwin, Homewood, Illinois.

Norbiato, G., Bevilacqua, M., RagGi, U., Micossi, P. \& Moroni, C. (1977) Metoclopramide increases plasma aldosterone concentration in man. Journal of Clinical Endocrinology and Metabolism, 45, 1313-1316.

Noth, R.H., MCCallum, R.W., Contino, C. \& Havelick, J. (1980) Tonic dopaminergic suppression of plasma aldosterone. Journal of Clinical Endocrinology and Metabolism, 51, 64-69.

PetTinger, W.A., Horwitz, D. \& SJoerdsma, A. (1963) Lactation due to methyldopa. British Medical Journal, i, 1460.

PratT, J.H., Ganguly, A. \& Weinberger, M.H. (1979) Metoclopramide-induced aldosterone stimulation: Independence from pituitary and renal factors. Clinical Research (Abstract), 27, 680A.

SEMPLE, P.F. \& MASON, P.A. (1978) Bromocriptine: Lack of effect on the angiotensin II and aldosterone responses to sodium deprivation. Clinical Endocrinology, 9, 155-161.

Whitfield, L., Sowers, J.R., TUCK, M.L. \& Golub, M.S. (1980) Dopaminergic control of plasma catecholamine and aldosterone responses to acute stimuli in normal man. Journal of Clinical Endocrinology and Metabolism, 51, 724-729. 
